\title{
Serological surveillance of measles in blood donors in Rio de Janeiro, Brazil
}

\author{
Rosângela Castro-Silva, ${ }^{1}$ Luiz Antonio Bastos Camacho, ${ }^{2}$ \\ Luiz Amorim, ${ }^{3}$ Andréia Dantas Medeiros, ${ }^{4}$ Daise Almeida Ferreira, ${ }^{4}$ \\ Solange Artimos Oliveira, ${ }^{5}$ and Marilda M. Siqueira ${ }^{4}$
}

ABSTRACT Objectives. To estimate the proportion of individuals seronegative for measles antibody among blood donors from a blood bank in the city of Rio de Janeiro, Brazil, and to describe their social and demographic characteristics, with the goal of exploring the potential use of plasma banks to supplement serological surveillance with relevant data in order to support the program of measles elimination in the city of Rio de Janeiro and elsewhere.

Methods. Plasma samples from 1101 consecutive blood donations made in November 2000 at HEMORIO, the largest blood bank in the state of Rio de Janeiro, were tested for measles immunoglobulin $G$, using a commercial enzyme immunoassay and a plaque reduction neutralization test. We calculated the proportion (and 95\% confidence interval (CI)) of samples seronegative for measles antibody for the total sample of blood donors and also for subgroups categorized by age, sex, neighborhood of residence, education, and occupation. We used the chisquare test to assess the statistical significance of differences in proportions and linear trends in proportions.

Results. Of the total group of blood donors, $6.9 \%$ of them (95\% CI: $5.4 \%-8.4 \%$ ) were seronegative for measles. Women had a higher proportion $(10.1 \%$; $95 \%$ CI: $6.8 \%-13.4 \%)$ of seronegative results than did men (5.6\%; $95 \%$ CI: 4.0\%-7.2\%). In terms of age, $86.8 \%$ of seronegative individuals were born between 1971 and 1982. Seronegativity was inversely proportional to age (chi-square $=58.0 ; \mathrm{P}<0.0001$ ). With regard to occupation, students had the highest proportion of seronegative individuals (17.8\%). In terms of education, most of the susceptible persons were in the categories of "incomplete university degree" or "incomplete high school." For the various areas of residence the proportions ranged from $2.1 \%$ to $11.4 \%$.

Conclusions. Blood bank plasma may constitute a useful and convenient source of complementary data for serological surveillance in adults of measles and other infections for which immunization and surveillance activities are implemented. This approach could be beneficial to other areas in Brazil and other countries where plasma from blood donors is available for surveillance. The use of residual sera from patients and plasma from blood donors represents a tradeoff between representativeness and timeliness as well as economy of resources.

Key words Measles, vaccination, blood donors, population surveillance, seroepidemiologic studies, Brazil.

1 Universidade Federal da Bahia, Faculdade de Medicina, Departamento de Patologia, Salvador, Bahia, Brazil.

2 Fundação Oswaldo Cruz, Escola Nacional de Saúde Pública, Rio de Janeiro, Rio de Janeiro, Brazil. Send correspondence to: Luiz A.B. Camacho, Escola Nacional de Saúde Pública,
R. Leopoldo Bulhões, 1480, Sala 820, Manguinhos, 21041-210 Rio de Janeiro-RJ, Brazil; telephone: 55 212598 2630; fax: 55212270 6772; e-mail: Luiz. camacho@ensp.fiocruz.br

3 HEMORIO, Rio de Janeiro, Rio de Janeiro, Brazil.

4 Fundação Oswaldo Cruz, Instituto Oswaldo Cruz, Deparatamento de Virologia, Laboratório de Virus
Respiratórios e Sarampo, Rio de Janeiro, Rio de Janeiro, Brazil.

5 Universidade Federal Fluminense, Hospital Universitário Antonio Pedro, Niterói, Rio de Janeiro, Brazil. 
Measles is considered an eradicable disease due to the existence of a single serotype, availability of effective vaccine, lack of naturally occurring nonhuman reservoirs, and availability of sensitive and specific diagnostic tools (1). In 1994 countries in the Region of the Americas set a goal of interrupting indigenous measles transmission by the end of 2000. With the enhanced measles vaccination strategy developed by the Pan American Health Organization, measles cases declined from approximately 250000 in 1990 to 2109 confirmed cases in 1996 (2). However, in 1997 there was a resurgence of measles in the Region of the Americas, with a total of 53683 confirmed cases, of which $97.4 \%$ were in Brazil. Over $50 \%$ of the cases occurred in adults aged 20-29 years (2). The outbreak was apparently triggered by imported measles cases, in a situation of relatively low vaccination coverage in infants, lack of follow-up campaigns, and large numbers of young adults with no previous contact with measles. In the measles outbreak in the state of São Paulo, Brazil, in 1997 most cases were unvaccinated young adults, including male workers who had migrated from rural areas, university students, health care workers, and military recruits (2). Outbreaks of measles in adults have been observed in other parts of the world as well $(3,4)$.

The high infectivity of measles is a major obstacle to interrupting the circulation of the virus through mass immunization. It is estimated that elimination of measles requires that a minimum of $94 \%$ of a population be immune. That implies $98 \%$ coverage with a vaccine that is $95 \%$ efficacious (5). In a large population with a high proportion of immunized individuals, subgroups with low vaccine coverage may provide "pockets of susceptibles" that have the potential for outbreaks (6). In addition, continuing circulation of the virus may lead to outbreaks of measles as susceptibles accumulate among older age groups as a result of failure to respond to vaccination (primary vaccine failures), decrease in antibody titers to undetectable levels after adequate response to vaccination (secondary vaccine failure), or missing vaccination and escaping natural infection. In England and Wales in 1994, serological surveillance detected an increased proportion of nonimmune school children, adding support for a recommendation of mass "catch-up" vaccination (7).

The strategy adopted in the Americas for eliminating measles is based on the intensification of vaccination in a two-dose approach with routine ("keep-up") vaccination, "catch-up" mass campaigns, and periodic followup campaigns, along with integrated laboratory and epidemiological surveillance of rash diseases (1). The component of those control measures with the most opportunities for improvement is surveillance (8). In a situation of very low incidence, surveillance of cases may not be enough to foresee and avert resurgence of the disease.

Serological surveys have proved to be important tools for measles surveillance, providing direct measures of the proportion of individuals who are immune through vaccination or natural infection (9). However, these surveys are expensive, time-consuming, and may become outdated shortly after the occurrence of an outbreak. An alternative approach, which has been used in England and Wales since 1987, relies on serological surveillance of opportunistic serum samples to provide profiles of past exposure for measles and several other infections (10). That program has proved useful for immunization policy decisions despite limitations in representativeness and lack of data on ethnic group, country of birth, and other covariates. In Brazil, Gaze et al. (11) demonstrated the feasibility, for epidemiological surveillance, of having sentinel laboratories use residues of blood collected for clinical laboratory tests to detect asymptomatic hepatitis A and B infections.

It is unusual to screen blood donors for serological markers of diseases that are not transmitted through transfusion of blood and blood-derived products. In South Australia a system of human sentinels, based on testing of sera from blood donors, was shown to be useful for epidemiological surveillance of an arbovirus (12). That study suggested that blood banks might be a convenient source of data for infectious diseases of public health importance, particularly among young adults.

We conducted a serological survey among blood donors from a blood bank in the city of Rio de Janeiro in order to: (1) estimate the proportion of individuals seronegative for measles antibody and (2) describe those persons' social and demographic characteristics. Located on the southeast coast of Brazil, the city of Rio de Janeiro has 5.5 million inhabitants and is the capital city of the state of the same name. We explored the potential use of plasma banks as a supplement to standard serological surveys of measles immunity. Data generated by our investigation would be relevant to the measles elimination program of the state of Rio de Janeiro if our data could indicate subgroups of the population with a proportion of susceptibles high enough to make them vulnerable to outbreaks of the disease.

\section{SUBJECTS AND METHODS}

Plasma aliquots from 1101 consecutive blood donations were obtained at HEMORIO, which is located in the city of Rio de Janeiro and is the largest blood bank in the state of Rio de Janeiro. HEMORIO collects approximately 100000 donations per year and stores plasma aliquots from all donors for 6 months. The most recent available blood donations from individuals living in the city of Rio de Janeiro were selected from HEMORIO's plasma bank. From HEMORIO's computerized records we obtained data on the age, sex, level of education, place of residence (the neighborhood of the subject's address), and occupation of the selected blood donors.

Blood donors at HEMORIO are required to give their consent for serologic screening for diseases transmitted by blood transfusion. Results from 
those routine laboratory tests as well as all other data collected in interviews are strictly confidential. We did not believe that additional consent specifically for serological tests for measles was necessary or practical since the results did not have diagnostic relevance, and no individual data would be disclosed. We reasoned that plasma samples that would have been discarded could be used to provide useful information with minimum cost and time, and with no additional discomfort for blood donors. The Ethics Committee of the Brazilian National School of Public Health (Escola Nacional de Saúde Pública) approved the research protocol.

\section{Laboratory methods}

A commercial enzyme immunoassay (EIA) (Enzygnost anti-measles virus/IgG, Dade Behring Marburg GmbH, Marburg, Germany) was used to detect human immunoglobulin G (IgG) antibody to measles virus in plasma. The tests were performed exactly as described in the manufacturer's protocol. Plasma samples with negative results by EIA were retested using a plaque reduction neutralization test (PRNT) to confirm the results. The EIA is considered an accurate test with high correlation to protection, but it is slightly less sensitive than the PRNT, which is regarded as the "gold standard" assay for detection of antibody against measles (13). The PRNT was conducted as previously described (14). Single titers greater than 120 are consistent with protection against clinical measles (15).

\section{Data analysis}

We calculated the proportion (and 95\% confidence interval) of individuals seronegative for measles antibody for the total sample of blood donors and also for subgroups categorized by age, sex, residence, education, and occupation. Serological status was presented for the most frequent occupa- tion categories in the entire sample. We merged neighborhoods into larger residence areas based on the neighborhoods' sample size and their proximity to each other. The proportion of blood donors seronegative for measles antibody was compared across subgroups of age, and the chi-square test was applied to assess the statistical significance of the differences and the linear trends in proportions. To test for interaction of age and sex the MantelHaenszel statistic was applied.

Sample size calculations were based on expected proportions of seronegativity for measles antibody in the range of $5 \%$ to $20 \%$, with a precision of 2.5 and 5.0 percentage points, respectively. With a conservative scenario $(20 \%)$, that level of precision could be achieved with about 300 individuals. We aimed for 1200 individuals, which could give us a safety margin for subgroup analysis. We used Microsoft Excel 97 software (Microsoft Corporation, Redmond, Washington, United States of America) for data entry and SPSS version 10 software (SPSS Inc., Chicago, Illinois, United States) for data analysis.

\section{RESULTS}

The results of plasmas tests from 1101 individuals who donated blood in November 2000 were available for analysis. Males made up $72 \%$ of the donors. The median age of the donors was 22 years, with a mean of 34.3 years (standard deviation $=10.6$ years). The vast majority of blood donors in our sample lived in central, northern, and western areas of the city, where mostly middle- and low-income persons live. The most frequently reported occupations were: student $(8.2 \%)$, military (8.1\%), "auxiliary" (performing support activities, mainly in offices or other business establishments) (7.4\%), housewife $(5.9 \%)$, driver (mainly bus and taxi) $(5.4 \%)$, civil servant $(3.8 \%)$, and a myriad of unskilled and semiskilled job categories such as painter, receptionist, and sales person. Skilled professionals comprised $3.8 \%$ of the sample; they included teachers $(1.8 \%$ of the sample), physiotherapists $(0.2 \%)$, and chemists $(0.2 \%)$. In terms of formal schooling, $6.4 \%$ reported a university degree, $8.1 \%$ were categorized as "incomplete university degree," and 29.3\% had completed high school. On the other hand, $23.9 \%$ did not complete elementary school.

The EIA was negative for measles antibody in 81 blood donors. In 57 of these 81 seronegative individuals there was enough plasma left to perform the PRNT, which detected 5 seropositives. Therefore, a total of 76 blood donors were seronegative for measles (76/ $1101=6.9 \%$; 95\% CI: 5.4\%-8.4\%).

In terms of age, $86.8 \%$ of the seronegative individuals (66 of 76) were born between 1971 and 1982 (Figure 1). Seronegativity was inversely related to age: $16.6 \%(95 \% \mathrm{CI}$ : $12.2 \%-21.0 \%$ ) for those $18-25$ years old, $6.3 \%$ (95\% CI: $3.8 \%-8.9 \%$ ) for those 26-35, and $1.7 \% \quad(95 \% \quad \mathrm{CI}$ : $0.4 \%-3.1 \%$ ) for those 36 and older (chisquare for linear trend (with 1 degree of freedom $)=58.0 ; P<0.0001)$.

Among female blood donors the proportion of seronegative results (10.1\%; 95\% CI: 6.8\%-13.4\%) was higher than among males (5.6\%; 95\% CI: $4.0 \%-7.2 \%)$. In the age group of 18-25 years the gender difference was even higher: $25 \%$ for women and $12 \%$ for men. The test for interaction of age and sex was not conclusive $(P=0.074)$.

Among the most frequently reported occupational groups in this sample, the proportion of seronegative individuals ranged from $0 \%$ to $17.8 \%$, with students being high above the overall proportion (Table 1).

In terms of education completed, most of the susceptible persons reported being in the category of incomplete university degree or of incomplete high school. Those two education categories had the highest proportion of seronegativity $(15.7 \%$ and $11.0 \%$, respectively). In the lowest educational level, not having completed elementary school, $3.7 \%$ were seronegative.

For the different areas of residence the proportion of seronegative individuals ranged from $2.1 \%$ to $11.4 \%$, 
FIGURE 1. Frequency distribution of blood donors according to year of birth and serological status for measles antibody, Rio de Janeiro, Brazil, 2000

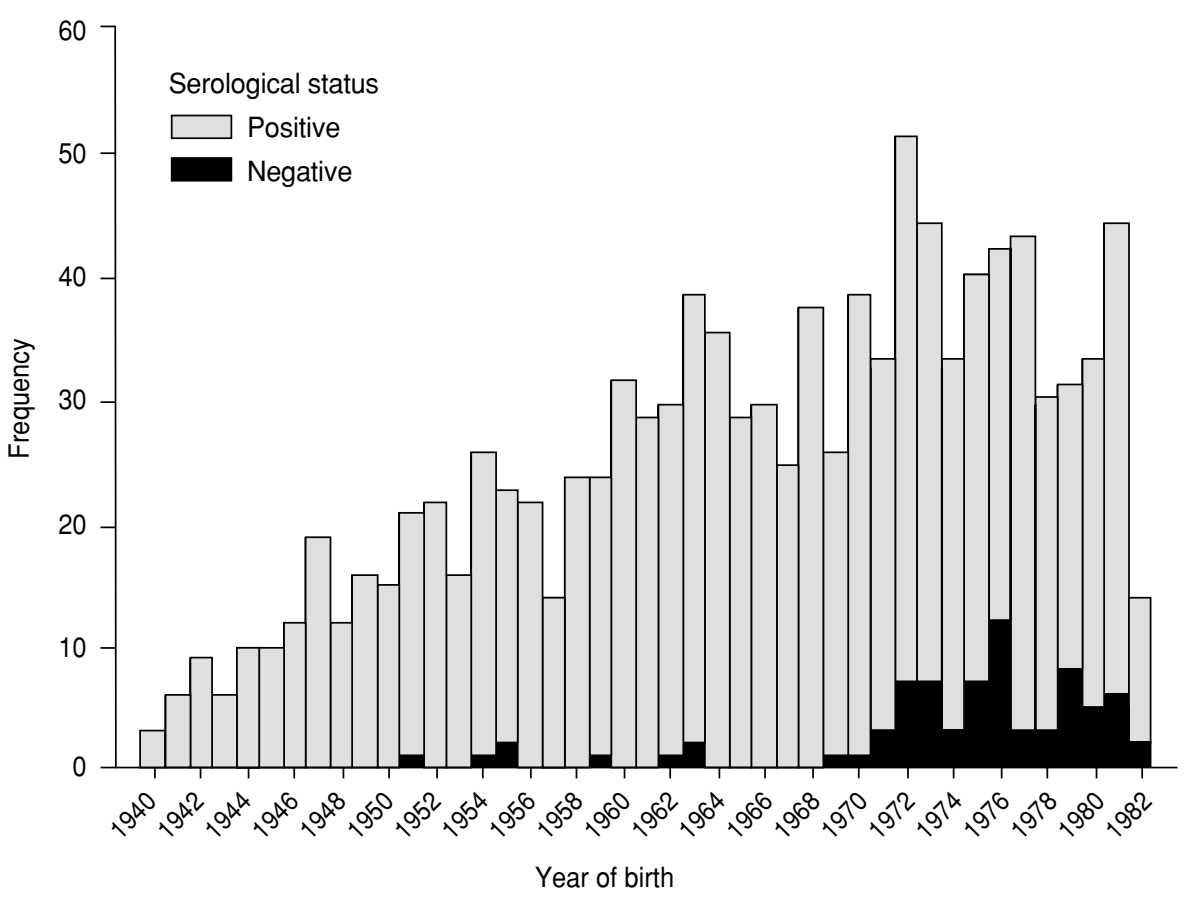

TABLE 1. Proportion of blood donors seronegative for measles antibody, in the most frequently reported occupational categories, Rio de Janeiro, Brazil, 2000

\begin{tabular}{lrrr}
\hline & & \multicolumn{2}{c}{ Seronegative } \\
\cline { 3 - 4 } Occupation & Total & No. & $\%$ \\
\hline Student & 90 & 16 & 17.8 \\
Housewife & 65 & 5 & 7.7 \\
Auxiliaryb & 81 & 5 & 6.2 \\
Driver & 60 & 3 & 5.0 \\
Military & 89 & 4 & 4.5 \\
Civil servant & 42 & 0 & 0 \\
Others & 674 & 43 & 6.4 \\
$\quad$ Total & 1101 & 76 & 6.9 \\
\hline
\end{tabular}

a Chi-square (with 6 degrees of freedom) $=21.235 ; P=$ 0.002 .

${ }^{\mathrm{b}}$ Auxiliary = performing support activities, mainly in offices or other business establishments

${ }^{c}$ Driver $=$ mostly bus and taxi drivers

with no apparent pattern in the geographical distribution.

\section{DISCUSSION}

Based on World Health Organization (WHO) recommendations for age- specific susceptibility levels in the WHO European Region, in order to interrupt measles transmission, the proportion of susceptible individuals must not exceed $15 \%$ in children aged $1-4$ years, $10 \%$ in those $5-9$ years old, and $5 \%$ in those 10 or older (16). That herd immunity threshold is a rough guideline, and it does not take into account special types of population aggregation (e.g., shantytowns), which have important implications for the transmission of infections (17). Serological surveillance contributes to assessing immunological status in populations, and discovering pockets of susceptibility helps both to avert outbreaks of communicable diseases and to evaluate the effectiveness of immunization programs. Where circulation of the virus is not apparent but remains a possibility, the susceptibility profile of a population may change rapidly. Therefore, serological surveillance must provide timely data in order to be useful for management purposes. The use of residual sera from patients and plasma from blood donors represents a tradeoff between representativeness and timeliness as well as economy of resources (10). Given the time generally required to produce results and the resources needed for sustained monitoring of the serological status of populations, blood donors had clear advantages as sources of specimens for serological surveillance of measles in the setting analyzed in this study.

The sample of blood donors analyzed in this study was made up of different cohorts of exposure to vaccine and/or natural infection, thus explaining their differences in susceptibility to measles. Individuals older than 35 years of age had a very low proportion of seronegativity, consistent with widespread natural infection prevailing in Brazil before routine immunization against measles was implemented in 1973. The age group of those 26-35 years old included individuals who lived in times of low vaccination coverage and persistent circulation of the measles virus, which explains their intermediate proportion of seronegativity. The age group of those 18-25 years old was more likely to have been vaccinated and less likely to have been exposed to natural infection than the older age groups. At the time that that youngest cohort became eligible for immunization against measles (during the late 1970s and early 1980s) vaccination coverage in the state of Rio de Janeiro and in Brazil overall ranged from $25 \%$ to $75 \%$ in children less than 1 year old, and measles outbreaks did occur (18). It is difficult to estimate the vaccination coverage for the persons in this age group because during their lifetime the opportunities for immunization provided by routine vaccination, vaccination in response to outbreaks, and mass campaigns varied among the areas of the country.

Vaccination coverage in Brazil was improved in the 1980s and was kept above $90 \%$ in the 1990s (18). The incidence of measles in the country has been very low except for outbreaks in 1990-1991 and 1997. As a result of reduced circulation of the measles virus, some proportion of individuals in the age group of $18-25$ years was 
spared natural measles infection and remained seronegative. They may have missed routine vaccination in their childhood and follow-up vaccination campaigns later on (part of this age group was eligible for the 1992 nationwide mass vaccination against measles). For those who had been vaccinated, seronegativity might be explained by (1) failure to seroconvert due to low potency of the vaccine, maternal antibodies, intercurrent clinical conditions, and other unknown reasons or (2) waning of immunity, which may occur even after a booster dose (18). The duration and intensity of vaccine-induced immunity is also affected by the strain of the vaccine virus.

Seronegative subjects may be a heterogeneous category in terms of susceptibility to measles since low antibody levels in vaccinated individuals are not always indicative of lack of clinical protection (19). There is empirical evidence that seronegativity by EIA and PRNT correlates with susceptibility, even though immunity that declined to below the threshold of the EIA might still be protective $(9,20)$. On the other hand the level of protection of seropositive subjects with lower antibody levels has been questioned (21). It has been suggested that levels of protection are a continuum rather than a dichotomous status (22). In seroprevalence studies it is not possible to distinguish between primary and secondary vaccine failure. For practical purposes in a situation where measles is close to being eliminated, it may be justified to target those subgroups known to be at greater risk of a measles outbreak because of their immunological status and the social and behavioral factors that favor spread of communicable diseases. For example, in the United States, vaccination against measles is recommended for the military and for college students (1), among whom most cases of measles in adults occur (3).

There is no biologically plausible explanation for the higher proportion of seronegative plasma among the females in our study. The lower average age of female blood donors and their higher educational levels explained part of the difference in seropositivity. However, that higher level of susceptibility has probably changed since we did our research in 2000 because that sex-age group was targeted in a nationwide vaccination campaign in 2001, using a combined rubella and measles vaccine (23).

Occupation and area of residence may help define the priorities for reducing susceptibility. Occupational groups, including health care workers and students, have been shown to play a major role in spreading infection (2, 24). The accumulation of susceptibles may be selective, with it occurring more often, for instance, in shantytowns and other low-income neighborhoods. This study does not provide data on this specific issue, but is seems plausible that such communities may contain a large enough number of susceptibles and have high enough contact rates to increase the epidemic potential.

A major concern with estimates from a sample of blood donors is their representativeness. Blood donors cannot include individuals under the age of 18 , thus excluding a subset of the population that is very relevant for seronegativity analysis. Moreover, the plasma specimens we analyzed were not a random sample of blood donations. They included all blood donations in a period of less than one month, from a selected subset of the adult population. Self-selection, interviewing to detect risk factors, and using blood tests for screening probably lead to choosing individuals who, in comparison to the general population, are younger, healthier, and less likely to have risk factors for infections transmitted through blood transfusion.

The overrepresentation of males in our sample is consistent with the profile of blood donors in most Brazilian blood banks. In HEMORIO, for instance, $80 \%$ of blood donors are male. However, none of the selection factors for blood donation seemed to have a direct association with seropositivity for measles. In other words, known characteristics of blood donors did not indicate that their serological status for measles is atypical. In fact, the ob- served proportions of seronegativity for measles antibody were plausible considering available data on the occurrence of the measles and vaccination activities.

Nevertheless, the selection factors mentioned above added uncertainty to the proportion of those susceptible to measles estimated from the blood bank samples. The validity of the estimates based on blood bank specimens selected from a specified area and time period might be assessed by comparison with results from serological surveys in a random sample of a population. A simple, rough approach to validating data from blood banks would be to compare estimates of the proportion of individuals susceptible to measles from samples of blood donations before and after a mass immunization campaign that included adults. If the campaign were successful, one could expect a reduction in the proportion of seronegative individuals. However, this does not necessarily mean that examining blood bank plasma before and after mass immunization campaigns would be appropriate for evaluating the performance of the campaigns.

Other data elements could expand the possibilities for analyzing blood bank plasma. These elements include history of vaccination against measles where vaccination cards or clinical records exist, as well as previous places and times of residence. These data are not collected routinely from blood donors, so the extra work to obtain them would have to be balanced against benefits that this additional information would provide in interpreting the immunological profile of the study group. Quantitative serological methods, including the EIA and the PRNT, would also be more informative of the immunological status of this subgroup of the population than the qualitative EIA used in this study.

Regardless of our methodological limitations, our data may indicate areas worth further investigation, for example, with additional serological surveys with groups not included among blood donors. Alternatively, additional surveys using blood bank plasma could 
oversample females so as to correct for gender imbalance among blood donors. Focusing on specific age groups, occupations, and areas of residence among blood donors over a time period longer than the one covered in this study would allow more in-depth analysis and more precise definition of subgroups deserving enhancement of surveillance and immunization activities.

Use of blood bank plasma was successful in the surveillance of arbovirus activity in South Australia (12). Serological surveillance in nonprobabilistic samples of the population in England and Wales (10) and in Italy (25) has provided useful approximations of the proportion of susceptible individuals, which proved invaluable for policy decisions. Likewise, the results of this study may strengthen the recommendation of the Pan American Health Organization and the Brazilian national immunization program of immunizing adult risk groups such as university students, military personnel, and young migrants from areas with circulation of the measles virus $(18,26)$.

We believe that our study has shown that blood bank plasma may constitute a useful and convenient source of complementary data for serological surveillance in adults of measles and other infections for which immunization and surveillance activities are implemented. This approach could also be beneficial with infections such as rubella, and in other areas in Brazil and in other countries where plasma from blood donors is available for surveillance.

Acknowledgements. We are highly indebted to Dr. Anna M.Y. Yamamura for carrying out the PRNT. This study was cosponsored by Projeto Pesquisa Estratégica/Escola Nacional de Saúde Pública/Fundação Oswaldo Cruz, Instituto Estadual de Hematologia Arthur Siqueira Cavalcanti - HEMORIO, Coordenação de Aperfeiçoamento de Pessoal de Ensino Superior, and Conselho Nacional de Desenvolvimento Científico Tecnológico.

\section{REFERENCES}

1. Measles eradication: recommendations from a meeting cosponsored by the World Health Organization, the Pan American Health Organization, and CDC. MMWR Recomm Rep 1997;46(RR-11):1-20.

2. de Quadros CA, Hersh BS, Nogueira AC, Carrasco $\mathrm{PA}$, Silveira $\mathrm{CM}$. Measles eradication: experience in the Americas. Morb Mortal Wkly Rep 1999;48(SU01):57-64.

3. Duclos P, Reed SC, Varughese P, Hersh BS. Measles in adults in Canada and the United States: implications for measles elimination and eradication. Inter J Epidemiol 1999;28: 141-146.

4. Miller M, Williams WW, Redd SC. Measles among adults, United States, 1985-1995. Am J Prev Med 1999;17:114-119.

5. Cutts FT, Henderson RH, Clements CJ, Chen RT, Patriarca PA. Principles of measles control. Bull World Health Organ 1991;69:1-7.

6. Measles outbreak-Netherlands, April 1999January 2000. MMWR Morb Mortal Wkly Rep 2000;49(14):299-303.

7. Gay N, Ramsay M, Cohen B, Hesketh L, Morgan-Capner P, Brown D, et al. The epidemiology of measles in England and Wales since the 1994 vaccination campaign. Commun Dis Rep CDR Rev 1997;7:R17-R21.

8. Brasil, Ministério da Saúde, Centro Nacional de Epidemiologia. Guia de campo para erradicação do sarampo e controle da rubéola. Brasília: Ministério da Saúde; 1999.

9. De Melker H, Pebody RG, Edumunds WJ, Lévy-Bruhl D, Valle M, Rota MC, et al. The seroepidemiology of measles in Western Europe. Epidemiol Infect 2001;126:249-259.

10. Osborne K, Gay N, Hesketh L, MorganCapner P, Miller E. Ten years of serological surveillance in England and Wales: methods, results, implications and action. Int J Epidemiol 2000;29:362-368.

11. Gaze R, Carvalho DM, Luiz RR, Servino VRR, Berro OJ, Bravim Y. Laboratórios sentinelasuma proposta para o monitoramento das infecções pelos vírus das hepatites A e B. Informe Epidemiológico do SUS 2000;9(1):5-21.

12. Weinstein P, Worswick D, Macintyre A, Cameron S. Human sentinels for arbovirus surveillance and regional risk classification in South Australia. Med J Aust 1994;160:494-499.

13. Albrecht P, Herrmann K, Burns GR. Role of virus strain in conventional and enhanced measles plaque neutralization test. J Virol Methods 1981;3:251-260.

14. Stefano I, Sato HK, Pannuti CS, Omoto TM, Mann G, Freire MS, et al. Recent immunization against measles does not interfere with the sero-response to yellow fever vaccine. Vaccine 1999;17:1042-1046.

15. Chen RT, Markowitz LE, Albrecht P, Stewart JA, Mofenson LM, Preblud SR, et al. Measles antibody: reevaluation of protective titers. J Infect Dis 1990;162:1036-1042.

16. World Health Organization. Strategic plan for the elimination of measles in the European Region. Copenhagen, Denmark: WHO Regional Office for Europe; 1997.

17. Fine P. Herd immunity: history, theory, practice. Epidemiol Rev 1993;15(2):265-302.

18. Brasil, Ministério da Saúde, Fundação Nacional de Saúde. Guia de vigilância epidemiológica. 5a edição. Brasília: FUNASA; 2002.

19. Cohn ML, Robinson ED, Faerber M, Thomas D, Geyer S, Peters S, et al. Measles vaccine failures: lack of sustained measles-specific immunoglobulin $G$ responses in revaccinated adolescents and young adults. Pediatr Infect Dis J 1994;13(1):3-8.
20. Gustafson TL, Lievens AW, Brunell PA, Moellenber RG, Buttery CMG, Sehulster LM. Measles outbreak in a fully immunized secondary-school population. N Engl J Med 1987; 316(13):771-774.

21. Davidkin I, Valle M. Vaccine-induced measles virus antibodies after two doses of combined measles, mumps and rubella vaccine: a 12year follow-up in two cohorts. Vaccine 1998; 16(20):2051-2057.

22. Cox MJ, Azevedo RS, Massad E, Fooks AR, Nokes DJ. Measles antibody levels in a vaccinated population in Brazil. Trans R Soc Trop Med Hyg 1998;92:227-230.

23. Brasil, Ministério da Saúde, Fundação Nacional de Saúde. Ministério da Saúde prorroga vacinação de mulheres contra rubéola [news release]. Available from: http://www. funasa.gov.br/not/not302.htm [Internet site]. Accessed 1 October 2002.

24. Lambert SB, Morgan ML, Riddell MA, Andrews RM, Kelly HA, Leydon JA, et al. Measles outbreak in young adults in Victoria, 1999. Med J Aust 2000;173:467-471.

25. Salmaso S, Gabutti G, Rota MC, Giordano C, Penna C, Mandolini D, et al. Patterns of susceptibility to measles in Italy. Bull World Health Organ 2000;78(8):950-955.

26. Organización Panamericana de la Salud. La erradicación del sarampión: guía práctica. Washington, D.C.: OPS; 1999.

Manuscript received 24 October 2002. Revised version accepted for publication on 13 May 2003 
RESUMEN Objetivos. Determinar la proporción de personas seronegativas a anticuerpos contra el sarampión entre los donantes de un banco de sangre de la ciudad de Río de Janeiro, Brasil, y describir sus características sociales y demográficas, con el fin de explorar el uso eventual de los bancos de plasma para complementar la vigilancia serológica con datos que permitan apoyar el programa de erradicación del sarampión en la ciudad de Río de Janeiro y en otras localidades.

Métodos. Se estudió la presencia de inmunoglobulinas G contra el sarampión en muestras de plasma de 1101 donaciones de sangre consecutivas realizadas en noviembre de 2000 en HEMORIO, el mayor banco de sangre del estado de Río de Janeiro, mediante un ensayo inmunoenzimático comercial y una prueba de neutralización por reducción de placas. Se calculó la proporción (y el intervalo de confianza (IC) de 95\%) de las muestras negativas a anticuerpos contra el sarampión en la totalidad de las donaciones y en subgrupos conformados según la edad, el sexo, el vecindario de residencia, la educación y la ocupación laboral. La significación estadística de las diferencias entre las proporciones y entre sus tendencias lineales se determinó mediante la prueba de ji al cuadrado.

Resultados. Del total de donantes de sangre, el 6,9\% (IC95\%: 5,4 a 8,4\%) resultó seronegativo al sarampión. Las mujeres tuvieron una mayor proporción de resultados seronegativos (10,1\%; IC95\%: 6,8 a 13,4\%) que los hombres (5,6\%; IC95\%: 4,0 a 7,2\%). En relación con la edad, 86,8\% de las personas seronegativas nacieron entre 1971 y 1982. La seronegatividad fue inversamente proporcional a la edad (ji al cuadrado = 58,0; $P<0,0001)$. En cuanto a la ocupación laboral, los estudiantes presentaron la mayor proporción de seronegativos $(17,8 \%)$, mientras que en lo referente a la educación, la mayoría de las personas susceptibles a la enfermedad se encontraban en la categoría de "estudios universitarios incompletos" o "estudios secundarios incompletos". La proporción de seronegativos entre las diferentes áreas de residencia estuvo entre $2,1 \%$ y $11,4 \%$.

Conclusiones. El plasma de los bancos de sangre puede ser una fuente útil y conveniente de datos complementarios para la vigilancia serológica en adultos, tanto de sarampión como de otras enfermedades infecciosas para las que se hayan implementado actividades de inmunización y vigilancia. Este enfoque puede ser beneficioso en otras regiones de Brasil y en otros países en los que se pueda contar para la vigilancia con el plasma de los donantes de sangre. El empleo del remanente de los sueros de los pacientes y del plasma de los donantes de sangre representa una solución de compromiso entre la representatividad y la oportunidad, y el buen uso de los recursos.

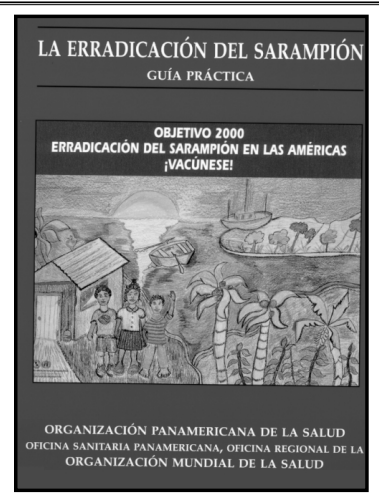

\section{La erradicación del sarampión: guía práctica}

Para ayudar a los países de las Américas a erradicar el sarampión de modo permanente, la OPS ha desarrollado una estrategia de vacunación para la prevención de brotes de la enfermedad. Este texto está especialmente diseñado como guía gerencial de organización y ejecución de actividades para el personal de salud que participa en actividades de erradicación del sarampión de alcance nacional, estatal y local. El libro incorpora los conocimientos adquiridos hasta ahora con las actividades de erradicación realizadas en el Caribe y América Latina entre 1987 y 1996, y destaca temas tales como la epidemiología y sintomatología de la enfermedad, el perfeccionamiento de la vigilancia, campañas especiales de vacunación, operaciones de barrido y respuesta a los brotes de sarampión. $1999 \cdot 71 \mathrm{pp}$. ISBN 9275330417 Código: CT 41 Precio: US\$ 14.00 Asimismo, describe someramente los servicios corrientes de vacunación y presenta modelos de formularios que se pueden adaptar a las necesidades locales. 